\title{
Mathematical modeling and forecasting of seasonal characteristics of tourist flow
}

\author{
Sherkul Rakhmanov ${ }^{1 *}$, Ibrohim Habibullaev ${ }^{2}$, Akbar Jumaev², and Tolib Turgunov ${ }^{3}$ \\ ${ }^{1}$ Tashkent Institute of Irrigation and Agricultural Mechanization Engineers, Tashkent, Uzbekistan \\ ${ }^{2}$ Tashkent Financial Institute, Tashkent, Uzbekistan \\ ${ }^{3}$ Tashkent State Agrarian University, Tashkent, Uzbekistan
}

\begin{abstract}
The article describes the flow of tourists to the Republic of Uzbekistan and the methods of analysis and forecasting based on econometric modeling of the development of the process based on its seasonal characteristics. Econometric modeling methods developed by foreign and local scientists were analyzed and divided into groups to analyze the process of changing the flow of tourists and predict the future number. Among them, the additive model in the group of time series reflecting the seasonality of tourist flow was found to meet the conditions. Based on the data obtained in the quarters for 2014-2018, the values of the trend $(\mathrm{T})$, seasonal $(\mathrm{S})$, and random (E) components of the time series were calculated step by step, and an additive model of the process was developed. Based on the developed model, the forecast values of tourist flow for the next quarter were determined, and the deviation from the actual value of the theoretical result was $20 \%$, and the occurrence of this deviation was clarified. Forecasts of changes in the statistics of the tourism sector have been developed. The article describes the methods of analysis and forecasting of tourist flows and seasonality of the Republic of Uzbekistan based on econometric modeling.
\end{abstract}

\section{Introduction}

According to the World Tourism Organization (WTO), tourism accounts for 11 percent of world GDP, 10 percent of an investment, 11 percent of global consumer spending, and 5 percent of tax revenues. With this in mind, in recent years in the Republic of Uzbekistan, as in various countries worldwide, great attention is paid to the development of tourism [1].

The number of foreigners visiting the Republic of Uzbekistan is growing year by year. Over the past 16 years, the number of foreign visits to Uzbekistan has reached 5,346.2 thousand people, which is 15.5 times more than in 2002 [6].

Several scientific studies are currently being conducted to study the development of tourism and its role in the economy. Issues of rational use of the potential of the tourism sector in ensuring sustainable development of countries V.G. Gulyaev, V.I. Krivoruchko, A.O. Varvashtyan, O.Suxarev, M. covered in the scientific works of Sinclair Scientific and theoretical bases of tourism development in our national economy and its integration into

*Corresponding author: rsherkul@inbox.ru 
the world market A.F. Saidov, I.S. Tuxliev, B.X. Turaev, O.H.Xamidov, Z.D. Odilova, Z.T. It has been studied in detail by Goibnazarovas. Modern problems of international tourism statistics and directions of statistical research in international tourism A.Yu. Aleksandrova, N.V. illuminated by Telepchenkova. Regional Approaches to Improving Tourism Statistics L.B. Maskanova, M.M. Proposed by the Dambuevas, their features are based on the N.O. studied by Starkova.

Some statistical indicators characterizing the tourism sector in the country, their problems of economic role in the statistical assessment of this sector T.P. Nikolaeva, A.O. are researched by Ovcharovas.

\section{Methods}

Methods for assessing the impact of tourism on the sustainable development of the economy, the analysis of the system of models used to address the issues of forecasting the development of tourism in Uzbekistan was conducted by NN Safarova.

The research work analyzed above serves as a basis for scientific theoretical research in tourism, which are more regional approaches based on average annual data and statistical methods.

The main indicators of the development of modern tourism are the country's tourism infrastructure and the flow of tourists to the country. Therefore, in making optimal management decisions in the field, it is important to study the seasonal nature of the flow of tourists and their quantitative assessment and forecasting.

Our research focuses on assessing and predicting their seasonal characteristics based on econometric modeling of the flow of tourists to the country.

\section{Results and Discussion}

The issue of forecasting in tourism has always been one of the main issues in scientific research. To date, based on more than 150 models in tourism, many indicators, such as the number of tourists, tourism revenues, the role of tourism in the economy, can be predicted in the short and long term.

Given that the problem of forecasting has become so deep and expansive, the forecasting models used in research over the years by several researchers have been studied, analyzed, and the advantages and disadvantages of each model have been highlighted.

While Crouch and Witt analyzed scientific research from 1960 to 1990 , forecasting methods and techniques in them, Gow and Law from 1995 to 2009, Song and Li from 2000 to 2007, Wu, Song and Shen from 2007 to 2015, TRRichard, H.Song, and J.Park analyzed the research from 1968 to 2018 and systematized the forecasting methods used in them.

The main purpose of forecasting is to analyze the trends of the indicators based on the values of the indicators in the past and to express the possible situation in the future.

Based on the significant findings from these studies, forecasting methods were divided into four groups (Figure 1).

The time series models used in tourism forecasting are further divided into two groups; the first group includes analytical leveling, seasonality detection, sliding methods, and the second group, which includes complex methods, includes autoregression models and grinding models. 


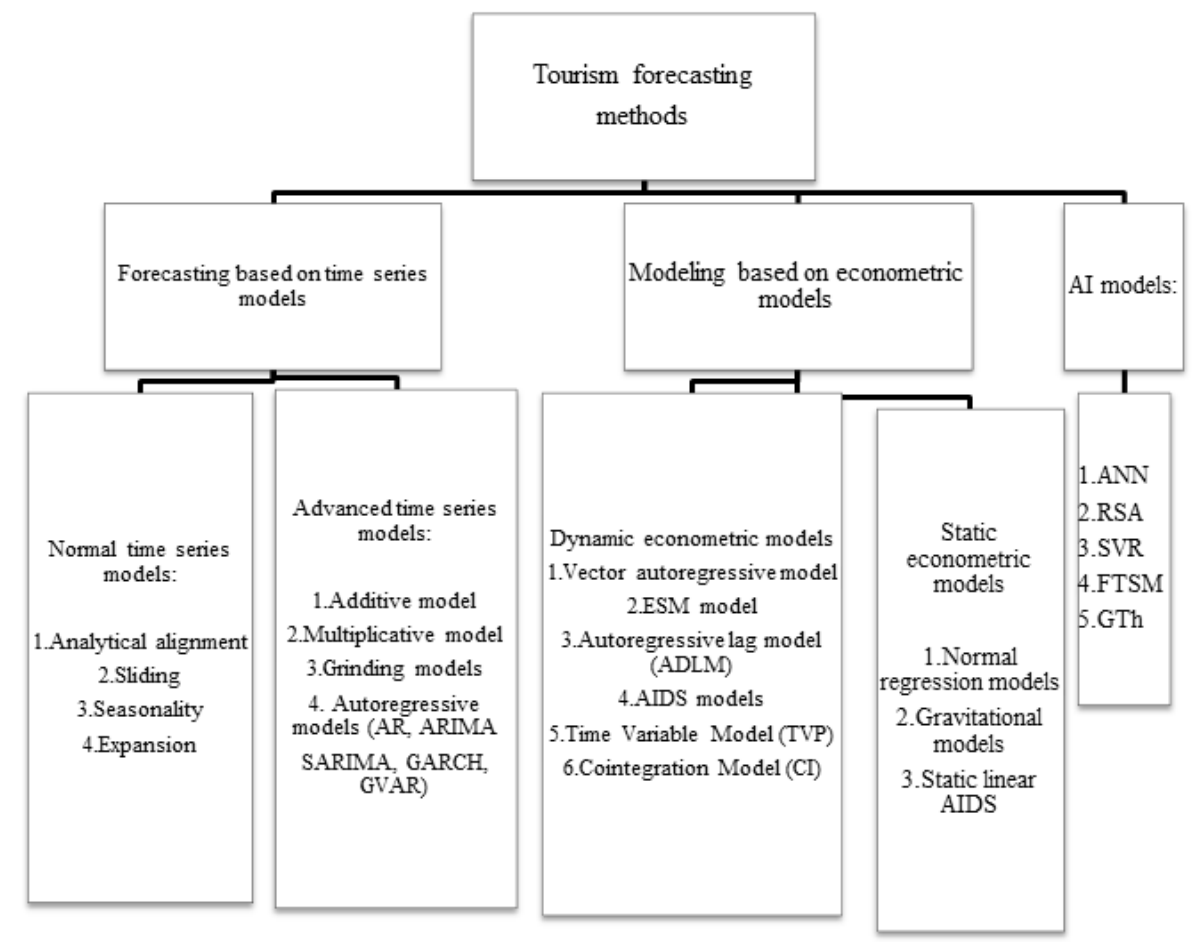

The most preferred model among such models is the additive model, which is expressed in the form of a sum of trends, seasonality, cyclicality, and random events that reflect the characteristics of a time series. Autoregression models are formed using lags. Dozens of new models have been introduced into the scientific community based on the Box-Jenks methodology, i.e., the combination of autoregressive and sliding additive models. It is known that their seasonality characterizes the statistics in the field of tourism. According to the State Statistics Committee of the Republic of Uzbekistan, the change in the number of foreign tourists visiting the Republic of Uzbekistan in 2014-2018 by quarter confirms our opinion (Table 1).

Table 1. Change in the number of foreign tourists visiting the Republic of Uzbekistan in 2014-2018

\begin{tabular}{|c|c|c|c|c|}
\hline \multirow{2}{*}{ Years } & \multicolumn{4}{|c|}{ Number of tourists by quarters } \\
\cline { 2 - 5 } & I & II & III & IV \\
\hline 2014 & 385837 & 475343 & 527363 & 473418 \\
\hline 2015 & 403996 & 494878 & 532033 & 486807 \\
\hline 2016 & 459803 & 490901 & 551753 & 524578 \\
\hline 2017 & 504970 & 620804 & 762304 & 801996 \\
\hline 2018 & 972264 & 1349369 & 1593844 & 1430742 \\
\hline All & 2726870 & 3431295 & 3967297 & 3717541 \\
\hline Average & 545374 & 686259 & 793459 & 743508 \\
\hline
\end{tabular}

* Source: Data of the State Statistics Committee of the Republic of Uzbekistan [5]

As can be seen from the data in the table, most of the tourist flow falls in the III quarter and a small part in the I quarter.

Processes with a seasonal character, expressed in time series, are studied by constructing additive or multiplicative models [3]. The additive model has a general view, in which each level $(\mathrm{Y})$ of the time series consists of a set of trend $(\mathrm{T})$, seasonal $(\mathrm{S})$, and 
random (E) components.

The construction of the model consisted of several steps; first of all, the corresponding seasonal components' values were determined by aligning the given data series with the method of averaging (Table 2, row 3). The condition that the sum of the mean values of the detected seasonal components is zero must be met [2]. However, since the sum of the mean values of the seasonal components is different from zero, i.e., equal to -29633.19 ($70396.59+20089.25+43988.40-23314.25=-29633.19)$, the correction factor is determined: $\mathrm{k}=-29633.19 / 4=-7408.30$. Using the correction factor, we calculate the values of the corrected seasonal components using the formula $S=\bar{S}_{i}-k$ (Table 2, row 4). The condition that the sum of the values of the corrected seasonal components is equal to zero is checked:

$$
-62988.29+27497.54+51396.70+(-15905.95)=0 .
$$

Table 2. Average seasonal flows for each quarter over the years

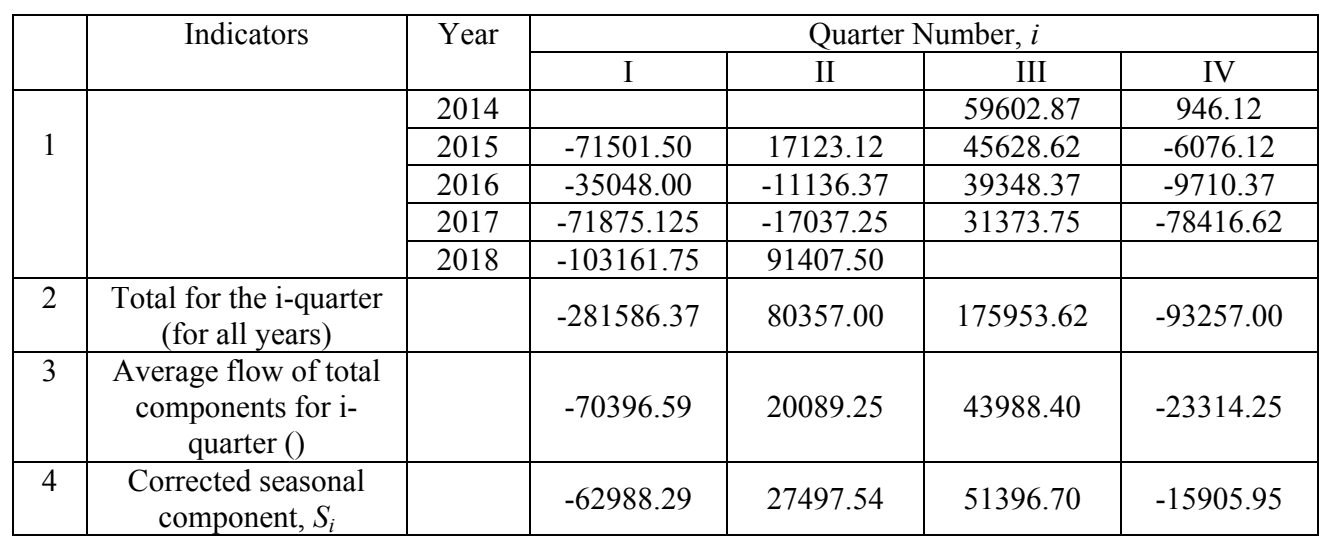

The condition is satisfied, which means that the values of the seasonal components are as follows:

$$
\begin{gathered}
\text { I - quarter: } \mathrm{S}_{1}=-62988.29 ; \mathrm{II} \text { - quarter: } \mathrm{S}_{2}=27497.54 \\
\text { III - quarter: } \mathrm{S}_{3}=51396.70 ; \mathrm{IV} \text { - quarter: } \mathrm{S}_{4}=-15905.95
\end{gathered}
$$

Using seasonal components (Table 3, column 3), the values of $\mathrm{T}+\mathrm{E}=\mathrm{Y}-\mathrm{S}$ are found by subtracting the effect of the innocuous components from each level of a given time series (column 4 of Table 3 ). These values consist only of trend and random components.

To determine the $\mathrm{T}$ component of the model, we analyze the line $(\mathrm{T}+\mathrm{E})$ using a linear trend. We have a linear trend represented by the following equation [3]:

$$
T=175557.86+49199.265 \cdot t
$$

By putting the values $\mathrm{t}=1,2, \ldots, 20$ in this equation, the time values (levels) of $\mathrm{T}$ for each quarter are found (column 5 in Table 3). 
Table 3. Texted Trend Values and Model Error (E)

\begin{tabular}{|c|c|c|c|c|c|c|}
\hline$t$ & $y_{t}$ & $\mathrm{~S}_{t}$ & $\begin{array}{c}T+E= \\
=\mathrm{y}_{t}-\mathrm{S}_{t}\end{array}$ & $T$ & $T+S$ & $\begin{array}{c}\mathrm{E}=y_{t}- \\
-(T+S)\end{array}$ \\
\hline 1 & 2 & 3 & 4 & 5 & 6 & 7 \\
\hline 1 & 385837 & -62988.29 & 448825.29 & 224757.1 & 161768.8 & 224068.2 \\
\hline 2 & 475343 & 27497.54 & 447845.46 & 273956.4 & 301453.9 & 173889.1 \\
\hline 3 & 527363 & 51396.70 & 475966.30 & 323155.7 & 374552.4 & 152810.6 \\
\hline 4 & 473418 & -15905.95 & 489323.95 & 372354.9 & 356449.0 & 116969.0 \\
\hline 5 & 403996 & -62988.29 & 466984.29 & 421554.2 & 358565.9 & 45430.1 \\
\hline 6 & 494878 & 27497.54 & 467380.46 & 470753.5 & 498251.0 & -3373.0 \\
\hline 7 & 532033 & 51396.70 & 480636.30 & 519952.7 & 571349.4 & -39316.4 \\
\hline 8 & 486807 & -15905.95 & 502712.95 & 569152.0 & 553246.0 & -66439.0 \\
\hline 9 & 459803 & -62988.29 & 522791.29 & 618351.3 & 555363.0 & -95560.0 \\
\hline 10 & 490901 & 27497.54 & 463403.46 & 667550.5 & 695048.1 & -204147.1 \\
\hline 11 & 551753 & 51396.70 & 500356.30 & 716749.8 & 768146.5 & -216393.5 \\
\hline 12 & 524578 & -15905.95 & 540483.95 & 765949.0 & 750043.1 & -225465.1 \\
\hline 13 & 504970 & -62988.29 & 567958.29 & 815148.3 & 752160.0 & -247190.0 \\
\hline 14 & 620804 & 27497.54 & 593306.46 & 864347.6 & 891845.1 & -271041.1 \\
\hline 15 & 762304 & 51396.70 & 710907.30 & 913546.8 & 964943.5 & -202639.5 \\
\hline 16 & 801996 & -15905.95 & 817901.95 & 962746.1 & 946840.2 & -144844.2 \\
\hline 17 & 972264 & -62988.29 & 1035252.29 & 1011945.4 & 948957.1 & 23306.9 \\
\hline 18 & 1349369 & 27497.54 & 1321871.46 & 1061144.6 & 1088642.2 & 260726.8 \\
\hline 19 & 1593844 & 51396.70 & 1542447.30 & 1110343.9 & 1161740.6 & 432103.4 \\
\hline 20 & 1430742 & -15905.95 & 1446647.95 & 1159543.2 & 1143637.2 & 287104.8 \\
\hline All & 13843003 & & & & 13843003 & 0 \\
\hline
\end{tabular}

Then, by adding seasonal components for the quarters corresponding to the trend $(\mathrm{T})$ levels, the theoretical values of the series according to the additive model are found (column 6 in Table 3).

The model process in which the time series constructed on the given (actual) values for tourist flow, the sum of the analytical textured trend and the theoretical values obtained in the model (columns 3 and columns 6), and the difference between them (table 3 column 7) is zero indicates an addictive reflection. The data in the graph and the results obtained show that the flow of tourists to our country tends to increase from year to year (Figure 1).

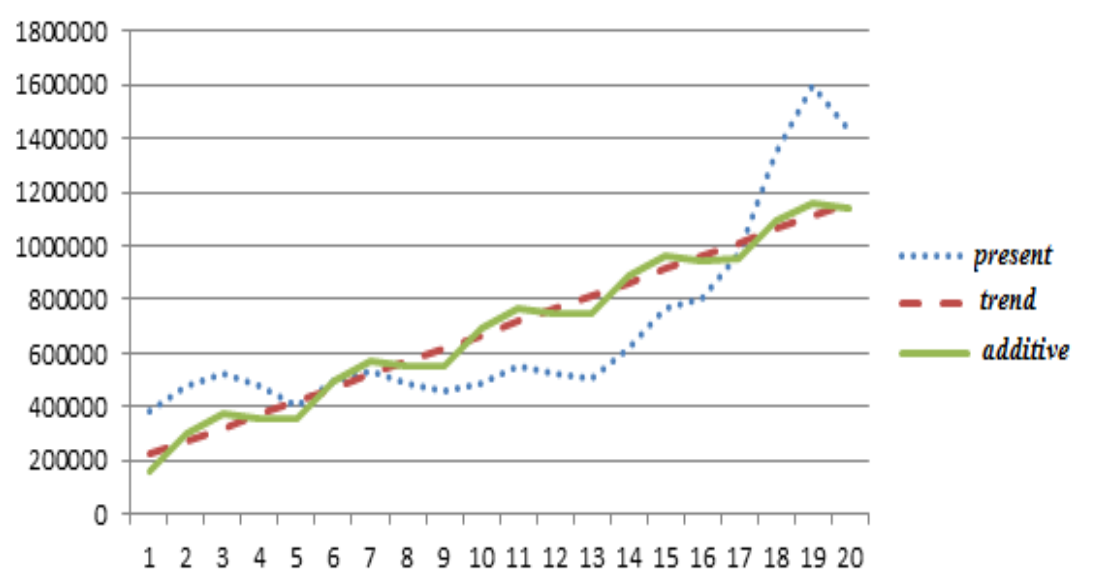

Fig.1. Tourists visiting the Republic of Uzbekistan flow dynamics 
According to the method of construction of the model, the model's error is calculated using the formula $\mathrm{E}=\mathrm{Y}-(\mathrm{T}+\mathrm{S})$ (Table 4, column 7). accuracy.

This leads to the conclusion that the model can be used to solve the problem of forecasting.

We can forecast the flow of tourists for each quarter of the year. Let us consider the forecast value of the number of tourists in the year following the period under study, i.e., in the I and II quarters of 2019 and in the first half of the year. To determine the values of the trend in the I and II quarters of 2019, we use the above trend equation. In our case, the trend $\mathrm{T}_{21}$ and $\mathrm{T}_{22}$ values for the first and second quarters of 2019, respectively. The trend for the forecast quarters is as follows:

$$
\begin{aligned}
\mathrm{T}_{21} & =175557.86+49199.265 \cdot 21=1208742.43 \\
\mathrm{~T}_{22} & =175557.86+49199.265 \cdot 22=1257941.70
\end{aligned}
$$

Taking into account the values of the seasonal components of the I and II quarters, the number of tourists in the I and II quarters of 2019, respectively: $V_{21}=\mathrm{T}_{21}+S_{1}=1208742,43$ $62988,29=1145754$ person;

$y_{22}=\mathrm{T}_{22}+S_{2}=1257941,70+27497,54=1285439$ person is formed. This means that the number of tourist visits in the first half of $2019(1,145,754+1,254,339)$ amounted to 243,1193 people.

According to the website of the State Committee for Tourism Development of the Republic of Uzbekistan, in the first half of 2019, the flow of tourists to the Republic amounted to 3034824 people [5]. It can be seen that the difference in the model result is $20 \%$. The reason for the sharp increase in the flow of tourists in the first half of 2019 is due to the ongoing reforms of the President of Uzbekistan in the field of tourism [2]. These figures show how well the model is structured. However, it should be noted that the forecast values can be calculated for a maximum of four years based on the given data, without changing the growth trend of the tourist flow.

To improve the forecast, forecasts for pessimistic (minimum), average and optimistic (maximum) cases for each year for 2020-2023 were developed (Table 4).

Table 4.Trends in the statistics of the tourism industry in the country

\begin{tabular}{|c|c|c|c|c|c|}
\hline № & Indicators & 2020 year & 2021 year & 2022 year & $\begin{array}{c}2023 \\
\text { year }\end{array}$ \\
\hline 1 & $\begin{array}{c}\text { Number of incoming } \\
\text { tourists, person }\end{array}$ & 6032213 & 7062986 & 8093760 & 9124533 \\
\hline 2 & $\begin{array}{c}\text { Revenues from tourism, \$ } \\
\text { billion }\end{array}$ & 1434.95 & 1526.09 & 1617.22 & 1708.35 \\
\hline 3 & Share in exports, \% & 10.36 & 11.37 & 12.38 & 13.39 \\
\hline 4 & $\begin{array}{c}\text { Employment in tourism, } \\
\text { man }\end{array}$ & 214125 & 223315 & 232505 & 241696 \\
\hline 5 & Share in GDP,\% & 2.74 & 2.81 & 2.89 & 2.96 \\
\hline
\end{tabular}

The results of the table show that in 2023 compared to 2020, the number of tourists (visitors) in the Republic increased by 3092320 people $(51 \%)$, revenues in the tourism sector to 274.4 billion US dollars (19\%), the share of tourism in exports by $3.03 \%$, the number of people employed in 27571 people ( 13\%), and its share in GDP will increase by $0.22 \%$. This shows the importance of tourism in the country's economy. 


\section{Conclusions}

The analysis of the obtained data once again showed that the tourism industry plays an important role in a market economy and in the diversification of the economy and more intensive research. The results of our research show that the application of statistical methods and process modeling in the field of tourism has been carried out mainly over the years. Based on this, the system of models used in tourism was methodologically and practically analyzed and classified. It was found that the additive model fully approximates the process of modeling the seasonal flow of tourists in the tourism industry, and based on the website of the State Committee for Tourism Development of the Republic of Uzbekistan, developed an econometric model of tourist flow in the country. As a result, it was shown that the flow of tourists has an upward trend. At the same time, the indicators of the tourism sector are projected for 2020-2023, and it was found that they have a growing trend.

\section{References}

1. Decree of the President of the Republic of Uzbekistan "On additional measures for the accelerated development of tourism in the Republic of Uzbekistan" dated 05.01.2019.

2. On additional organizational measures to create favorable conditions for the development of tourism potential of the Republic of Uzbekistan February 3, 2018 PF 5326

3. Decree of the President of the Republic of Uzbekistan dated February 7, 2017 "On the Strategy for the Further Development of the Republic of Uzbekistan". Collection of legislation of the Republic of Uzbekistan, (2017).

4. Fundamentals of Econometrics, Textbook, I.H. Habibullaev, B.Q, Utanov; -T, "Economy-Finance", 2018, -172 p.

5. Habibullaev I., Jumaev A. Modeling and forecasting of tourist flow and its seasonal processes in Uzbekistan. Scientific-practical and theoretical journal "Innovative development in the economy", 2, "ECONOMIC WORLD" pp. 61-67. (2019).

6. Sh Rahmanov, T T Turgunov, Z K Kusharov, and A A Mengnorov, Econometric methods for solving problems of analysis and forecasting dynamics of yield of agricultural crops, ICECAE 2020, IOP Conf. Series: Earth and Envi ronmental Science 614 (2020) 012165, IOP Publishing, doi:10.1088/1755-1315/614/1/012165

7. Turgunov T., Gaibnazarov S. Econometric methods for solving problems of agroeconomic forecasting: Science, technology and education. 4 (57), , pp. 72-76. (2019)

8. Bulletin of the State Statistics Committee of the Republic of Uzbekistan.www.stat.uz.

9. State Committee for Tourism Development of the Republic of Uzbekistan https://uzbektourism.uz/uz/research

10. Christopher Dougherty. Introduction to Econometrics. Oxford University Press,. p. 573. (2011).

11. Gujarati D.N. Basic Econometrics. McGraw-Hill, 5th edition,. p. 922. (2009).

12. Abdurahimov A., Turgunov T., Khaitmatov Yu. Possibilities of using the theory of indefinite ligaments in modeling and forecasting economic processes. "The role of information and communication technologies and the modernization of the national economy." Abstracts of the International Scientific and Practical Conference, TSEU, T., , pp. 97-101. (2011)

13. Briiko V.G., Pshenichnikov A.A. Modern problems of forecasting and developing agriculture, Journal of Basic Research, 12 (4), p. 762-765. (2015)

14. Castles O.O. Mathematical methods and models. M .: DiS, (2011). 
15. Ismikhanov Z.N., Umargadzhieva N.M., Magomedova M.A., Nurmagomedova L.A. Econometric models for forecasting socio-economic indicators of the development of the region, Fundamental research. (12-4). pp.785-789. (2015)

16. Pridvorova E.S. Comparative analysis of methods for forecasting the socio-economic development of the region, Scientific methods. Belgorod State University. Series: History. Political science. Economy. Informatics,. 1, (25). pp. 5-14. (2013)

17. Khachev M.M. Temmoeva S.A. Econometric model for forecasting the development of agricultural regions, International Journal of Applied and Fundamental Research, 9, pp. 163-167. (2017)

18. Chulkova E.A. Econometric models in the study of agricultural production in the region, Bulletin of the Orenburg State Agrarian University. 29-1. (1). pp. 118-121. (2011).

19. Eldyaeva N.A. Econometric methods in macroeconomic analysis: problems of building forecasting models, Journal: Bulletin of the Astrakhan State Technical University. Astrakhan, 4., pp. 225-230. (2006)

20. M. Kendal, A. Stewart "Multidimensional statistical analysis and time series" M. "Science", p. 736. (1976). 